Global Conferences Series:

Social Sciences, Education and Humanities (GCSSSEH), Volume 6, 2020

International Conference Fakultas Tarbiyah dan Keguruan Universitas Islam Negeri Imam Bonjol Padang (ICFTKUINIBP) 2020

DOI: https://doi.org/10.32698/icftk399

\title{
Learning Models of Islamic History based on Diversity (PSI-Bk) an Alternative of Learning Freedom in the 4.0 Era of Industrial Revolution
}

\section{Model Pembelajaran Sejarah Islam Berbasis Kebhinekaan (PSI-BK) Sebuah Alternatif Merdeka Belajar di Era Revolusi Industri 4.0}

\author{
Heri Effendi ${ }^{\mathrm{a}}$, SitiAisyah ${ }^{\mathrm{a}}$, Muspradi ${ }^{\mathrm{b}}$, Muslim ${ }^{\mathrm{c}}$, Januardi Rosyidi Lubis ${ }^{\mathrm{d}}$ \\ ${ }^{a}$ Institute of Education on Tapanuli Selatan, Padangsidimpuan, Indonesia, ${ }^{b}$ Sekolah Tinggi Keguruan dan \\ Ilmu Pendidika Adzkia, Padang, Indonesia, ${ }^{c}$ Universitas Bung Hatta, Padang, Indonesia, ${ }^{d}$ Sekolah Tinggi \\ Manajemen Informatika dan Komputer Citra Mandiri, Padangsidimpuan, Indonesia \\ E-mail: effendiheri550@gmail.com
}

\begin{abstract}
A College is ideally as a spring for the progress and development of the nation, its presence directly contributes to the nation's culture and civilization. The Learning Freedom Policy has actually become a new culture in implementing an autonomous and innovative teaching and learning process based on the needs of life. Learning freedom can form superior resources and quality to complete educational opportunities in the Industrial 4.0 era. In the learning process, so far the educational ecosystem tends to touch less the realm of learning freedom for students towards the development of logical reasoning, character, innovation, independence, comfort, and student expertise. The purpose of this research is to provide a descriptive learning model of Islamic history based on diversity (PSI-BK) an alternative of learning freedom in the 4.0 era of industrial revolution. The method used in this research is Sugiyono's R\&D model with the following steps; 1 ) potential and problems), (2) data collection, (3) product design, (4) design validation, (5) fixing designs, (6) product testing, (7) product revisions, (8) product testing, (9) product revision, (10) mass product manufacture. Subjects and research objects for the first year of 2019,they are students of history education study program at the Institute of Education on Tapanuli Selatanand PPKN students at Bung Hatta University. The results show that it is important for a college to implement the right learning model in construct diversity and freedom of learning in the 4.0 era of the industrial revolution. The learning model of Islamic history based on diversity (PSI-BK) is an alternative to contruct learning freedom in the 4.0 era of industrial revolutionthrough this models students are expected to have (1) good tolerance, (2) collaborative skills, (3) polite communication, and (4) good understanding of the material.
\end{abstract}

Keywords: PSI-BK model, independent learning, 4.0 industrial revolution

\section{PENDAHULUAN}

Perguruan tinggi idealnya sebagai mata air bagi kemajuan dan pembangunan bangsa, kehadirannya turut mewarnai kebudayaan dan peradaban bangsa secara langsung. Kebijakan merdeka belajar sejatinya menjadi kultur baru dalam pelaksanaan proses belajar mengajar yang otonom dan inovatif berbasis kebutuhan hidup. Merdeka belajar dapat membentuk sumber daya yang unggul dan berkualitas untuk menuntaskan peluang pendidikan pada era Industri 4.0.

Pendidikan Tinggi di era Revolusi Industri 4.0 memerlukan perubahan cara pandang pendidikan tinggi yang bersifat mendasar. Bentuk perubahan-perubahan tersebut, dilakukan dalam beberapa hal, diantaranya: (a) Perubahan dari berpikir hanya fokus tentang kehidupan masyarakat lokal menjadi berpikir ke masyarakat global (dunia), (b) Perubahan dari kompetisi semata menjadi partisipasi, sinergi, dan kolaborasi yang saling menguntungkan serta dijiwai semangat demokratisasi dalam pendidikan dan praktek

Copyright ( $) 2020$, the Authors. Published by Redwhite Press. 
berkewarganegaraan, dan(c) perubahan dari mengejar pertumbuhan ekonomi ke perkembangan kemanusiaan untuk menciptakan keadilan sosial dengan senantiasa menggerus ketimpangan dengan pemerataan (Effendi, H dkk, 2020: 13).

Agar perubahan tersebut mencapai sasarannya, maka pendidikan tinggi harus melaksanakan Empat pilar pendidikan UNESCO yang sudah mendunia, namun belum sepenuhnya diterapkan oleh seluruh negara, yaitu learningto know, learning to do,learningtobe dan learningto live together sebagaisatu kesatuan utuh, holistik dan komprehensif. Wujud konkritnya, Perguruan tinggi mengakomodasi keempat pilar tersebut dalam proses pembelajaran yang sesuai dengan perkembangan proses kognitif, afektif, dan psikomotor mahasiswa. (Laksana, S. D. 2016: 46)

Selanjutnya Aunurrahman (2019:143) menambahkan bahwa model-model pembelajaran dikembangkan utamanya beranjak dari adanya perbedaan berkaitan dengan berbagai karakteristik mahasiswa. Karena mahasiswa memiliki berbagai karakteristik kepribadian, kebiasaan-kebiasaan, modalitas belajar yang bervariasi antara individu yang satu dengan yang lainnya, maka model pembelajaran guru juga harus selayaknya tidak terpaku hanya pada model tertentu, akan tetatapi harus bervariasi.

Yamin, M., \& Syahrir, S. (2020: 126). Revolusi Industri 4.0 berpengaruh terhadap sejarah, secara substansi yang menyebabkan semakin kompleksnya sumber-sumber sejarah maupun proses belajarannya. Perkembangan tersebut mulai dari metode, media, model pembelajaran yang bersifat inovatif, sampai dengan substansi materinya sering menimbulkan kontroversial.

Perkembangan teknologi seakan dunia ini sudah ada digenggaman kita sehingga dengan mudah berbagai informasi kesejarahan dapat diperolehnya. Pebelajaran sejarah tidak mungkin mengabaikan semua itu, walaupun tidak semuanya berdampak positif bagi siswa/mahasiswa sejarah, guru sejarah, maupun sejarawan. Mereka hendaknya bisa selektif dalam menyikapi berbagai perkembangan akan ketersediaan informasi kesejarahan (Arifin, S., \& Muslim, M. O. H. 2020: 98).

Kolaborasi dan elaborasi antara sejarah dengan bidang ilmu yang lain terus dilaksanakan untuk melihat berbagai perubahan dan perkembangan (change and development) dimasyarakat dalam berbagai bidang. Apakah perkembangan di bidang ekonomi, politik, sosial dan budaya sehingga sejarah tidak bersifat mono-perspektif, tetapi multi-perspektif. Dengan demikian pembelajaran sejarah akan memberikan informasi yang komprehensip, integrited, dan itulah disebut sejarah total (total history).

Dengan datangnya era Revolusi Industri 4.0 memunculkan permasalah baru lagi yaitu bagaimana dengan perkembangan teknologi informasi seorang pengajar sejarah mampu menggunakan teknologi dengan tepat guna dan menyampaikan materi sejarah yang berdaya guna. Pendidikan Merdeka Belajar merupakan respon terhadap kebutuhan sistem pendidikan pada era Revolusi Industri 4.0. Pendidikan 4.0 dikenal sebagai sebuah inovasi yang bercirikan pada student centered. Pendekatan ini tidak hanya dapat mengembangkan siswa yang berpengetahuan luas tetapi juga mampu membuat pola pikir baru yang mampu merespon tantangan kehidupan, meningkatkan kreativitas serta inovasi di berbagai aspek kehidupan. (Tan et al., 2018, pp. 65-66 dalam ARIFIN, S., \& Muslim, M. O. H. (2020:2)

Dalam situasi dan kondisi di atas, umat Islam paling tidak dihadapkan pada dua permasalahan besar yaitu mampukah Islam melahirkan umat yang memiliki kompetensi spiritual dan agama yang bagus (ulama) serta umat yang unggul dalam intelektualitas modern. Realitas yang ada sekarang adalah sebagian besar pendidikan hanya membidik satu sisi antara ilmu agama atau ilmu pengetahuan umum. Hal ini menjadi ironi apabila umat Islam melihat sejarah peradaban Islam beberapa abad yang lal dimana pendidikan Islam klasik mampu melahirkan sosok yang memiliki kematangan ilmu keagamaan dan kematangan ilmu pengetahuan umum. Sehinga muncul keseimbangan antara daya pikir dan dzikir yang menjadi dasar kemajuan peradaban Islam dimasa itu (Kusworo, Budi. 2018)/

Tragis memang sampai sekarang masih terdapat kesan bahwa pembelajaran sejarah dan sejarah Islam membosankan karena hafalan nama-nama tokoh, tahun, dan sebagainya, itu semua adalah masalah klasik. Padahal mencermati "sejarah pembelajaran sejarah", bahwa mata pelajaran sejarah menduduki posisi sejak zaman Pergerakan Indonesia dan sudah diperkenalkan oleh Partai Nasional Indonesia tahun 1927 (Dekker, 1975:56).

Tidak ada cara yang terbaik dalam proses pembelajaran sejarah, dengan cara pandang ini maka tiga prinsip yang harus ada dalam pengembangan model PSI-BK adalah (a) Memandang pengetahuan sebagai satu hal yang belum sempurna,(b) Memandang proses belajar sebagai proses untuk merekonstruksi dan mencari pengetahuan yang akan dipelajari; serta (c) Memandang proses pembelajaran bukan sebagai proses pengajaran semata dilakukan secara klasikal, dan bukan merupakan suatu proses untuk menjalankan sebuah instruksi baku yang telah dirancang. Proses pembelajaran adalah proses dimana dosen menyediakan berbagai macam strategi dan metode pembelajaran dan paham akan pendekatan pembelajaran mahasiswanya untuk dapat) mengembangkan potensi yang dimilikinya (Sailah, dkk. 2014:54). 
Berangkat dari permasalahan di atas, menarik untuk di telaah lebih dalam bahwa pentinya Model Pembelajaran Sejarah Islam Berbasis Kebhinnekaan (PSI-BK) sebuah Alternatif Merdeka Belajar di Era Revolusi Industri 4.0.

\section{METODE}

Selanjutnya untuk mencapai tujuan dan target yang sebutkan, dalam penelitian ini dilaksanakan penelitian pengembangan model Sugiyono, dengan langlah-langlah (1) potensi dan masalah), (2) pengumpulan data, (3) desain produk, (4) validasi desain, (5) perbaiki desaian, (6) perbaiki desaian, (7) revisi produk, (8) uji coba produk, (9) revisi produk, (10) pembuatan produk masal. Analis potensi dan masalah dilakukan telaah kurikulum yang digunakan di IPTS dan Universitas Bung Hatta. Pengumpulan data di dilakukan dengan cara studi lapangan studi pustaka, analisis awal-akhir untuk menganalisis kurikulum, teori belajar dan pembelajaran dan mata kuliah serta materi perkuliahan yang relevan dengan sejarah Islam, melalaui wawancara langsung dengan mahasiswa, dosen. Kemudian dianalisis teori belajar yang melandasi model PSI-BK maka akan diperoleh deskripsi model PSI-BK yang dianggap ideal. Desain produk bertujuan untuk menyiapkan prototipe model PSI-BK dan perangkat PSI-BK yang efektif dan praktis. Pada tahap validasi desain dilakukan validasi terhadap validator, simulasi/uji keterbacaan dan Uji-coba lapangan. Uji coba dilakukan 3 (tiga) kali pelaksanaan, pertama di Institut Pendidikan Tapanuli Selatan dan di Universitas Bung Hatta. Perbaikan desain yakni dilakukan perbaikan dan penyempurnaan model PSI-BK sesui masukan ahli. Penerapan ujicoba pemakaian dari model PSI-BK adalah dengan rancangan penelitian jenis penelitian eksperimen dengan rancangan pretes posttest control group design. Selanjutnya dilakukan tahap penyebaran yang merupakan sosialisi model PSI-BK dan perangkat pembelajaran yang telah diujicobakan di Institut Pendidikan Tapanuli Selatan,dan Universitas Bung Hatta. Revisi produk PSI-BK terhadap kelemahan produk yang telah di uji cobakan untuk dilakukan penyempurnaan. Terakhir pembuatan produk masal, pada tahapan inidibuat draf model PSI-BK dan perangkat pembelajaran yang Valid, Praktis dan Efektif yang merupakan draft final.

\begin{tabular}{|c|c|c|c|c|}
\hline \multirow{3}{*}{ Sikap } & Sangat Baik & Baik & CukupBaik & KurangBaik \\
\hline & \multicolumn{4}{|c|}{ SKOR } \\
\hline & 4 & 3 & 2 & 1 \\
\hline Toleransi & 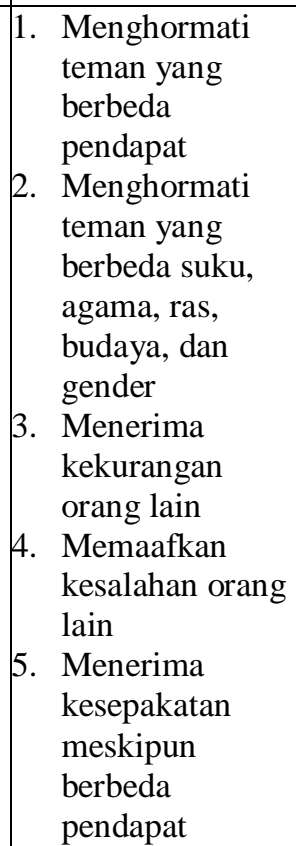 & 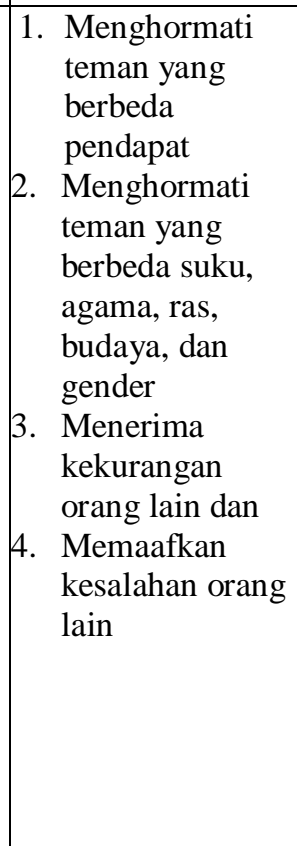 & $\begin{array}{ll}\text { 1. } & \begin{array}{l}\text { Menghormati } \\
\text { teman yang } \\
\text { berbeda } \\
\text { pendapat }\end{array} \\
\text { 2. } & \begin{array}{l}\text { Menghormati } \\
\text { teman yang }\end{array} \\
\text { berbeda suku, } \\
\text { agama, ras, } \\
\text { budaya, dan } \\
\text { gender } \\
\text { Menerima } \\
\text { kekurangan } \\
\text { orang lain }\end{array}$ & 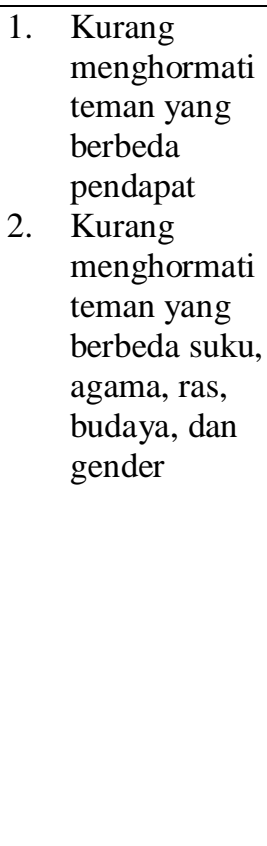 \\
\hline
\end{tabular}




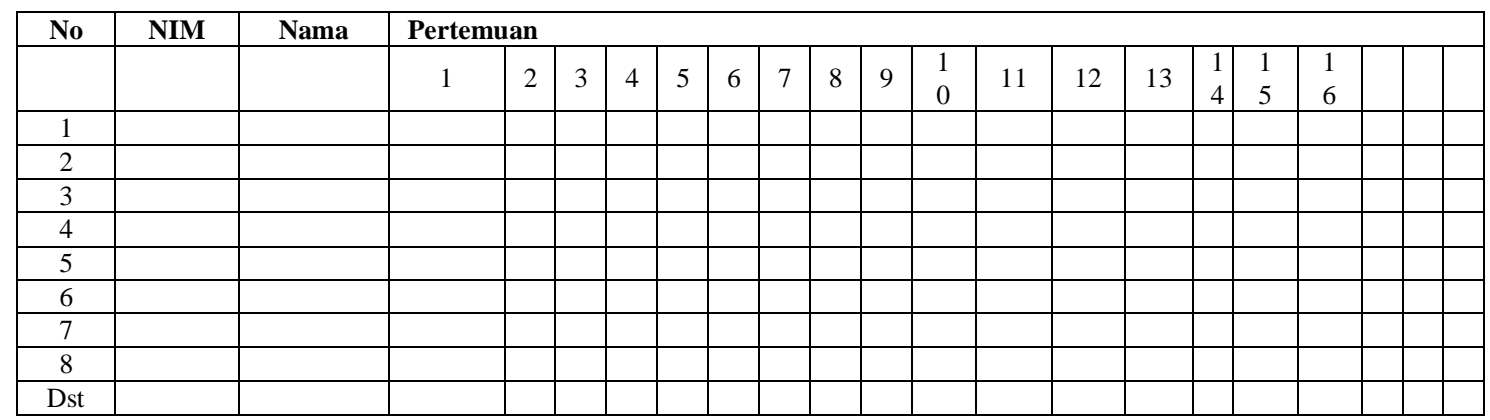

\section{HASIL DAN PEMBAHASAN}

Dalam rangka menyiapkan mahasiswa menghadapi perubahan sosial, budaya, dunia kerja dan kemajuan teknologi yang pesat, kompetensi mahasiswa harus disiapkan untuk lebih gayut dengan kebutuhan zaman. Link and match tidak saja dengan dunia industri dan dunia kerja tetapi juga dengan masa depan yang berubah dengan cepat. Perguruan Tinggi dituntut untuk dapat merancang dan melaksanakan proses pembelajaran yang inovatif agar mahasiswa dapat meraih capaian pembelajaran mencakup aspek sikap, pengetahuan, dan keterampilan secara optimal dan selalu relevan.

Kebijakan Merdeka Belajar- Kampus Merdeka diharapkan dapat menjadi jawaban atas tuntutan tersebut. Kampus Merdeka merupakan wujud pembelajaran di perguruan tinggi yang otonom dan fleksibel sehingga tercipta kultur belajar yang inovatif, tidak mengekang, dan sesuai dengan kebutuhan mahasiswa (Wulandari, dkk. 2019: 20)

Pendidikan Merdeka Belajar merupakan respon terhadap kebutuhan sistem pendidikan pada era Revolusi Industri 4.0. Di era Revolusi Industri 4.0 kebutuhan utama yang ingin dicapai dalam sistem pendidikan atau lebih khusus dalam metode pembelajaran yaitu siswa atau peserta didik yaitu penguasaan terhadap literasi baru. Literasi baru tersebut yaitu. Pertama, literasi data. Kedua, literasi teknologi. Terakhir, literasi manusia.

Progresivisme melihat bahwa berpikir dengan kecerdasan adalah pegangan utama dalam pendidikan. Hal ini akan memiliki makna lebih, apabila kecerdasan yang dimaksud adalah kecerdasan dalam konteks multiple intellegences. Dengan kata lain, kecerdasan yang dikembangkan bukan hanya kecerdasan yang bersifat linear matematis tetapi kecerdasan multidisiplin yang memiliki cakupan lebih luas (Barnadib, 1997: 29). Dalam konteks ini peserta didik tidak hanya dipandang sebagai individu, tetapi dipandang sebagai manusia yang berada dalam lingkungan sosial yang lebih luas.Saat ini kreativitas dan inovasi menjadi kata kunci penting untuk memastikan pembangunan Indonesia yang berkelanjutan. Para mahasiswa yang saat ini belajar di Perguruan Tinggi, harus disiapkan menjadi pembelajar sejati yang terampil, lentur dan ulet (agile learner). Kebijakan Merdeka Belajar Kampus Merdeka yang diluncurkan oleh Menteri Pendidikan dan Kebudayaan merupakan kerangka untuk menyiapkan mahasiswa menjadi sarjana yang tangguh, relevan dengan kebutuhan zaman, dan siap menjadi pemimpin dengan semangat kebangsaan yang tinggi.

Pembelajaran dalam Kampus Merdeka memberikan tantangan dan kesempatan untuk pengembangan kreativitas, kapasitas, kepribadian, dan kebutuhan mahasiswa, serta mengembangkan kemandirian dalam mencari dan menemukan pengetahuan melalui kenyataan dan dinamika lapangan seperti persyaratan kemampuan, permasalahan riil, interaksi sosial, kolaborasi, manajemen diri, tuntutan kinerja, target dan pencapaiannya. Model pembelajaran sejarah Islam Berbasis Kebhinnekaan (PSI-BK) sebuah alaternetif Merdeka Belajar di Era Revolusi Industri 4.0.

Berdasarkan teks dan konsteks di atas, perlu di jawab pertanyaan bahwa bagaimana dampak langsung yang di bangun dalam Model pembelajaran sejarah Islam Berbasis Kebhinnekaan (PSI-BK) sebuah alaternetif Merdeka Belajar di Era Revolusi Industri 4.0? Bagaimana relasi dengan merdeka belajar di kampus merdeka di era revolusi industri 4.0?

Effendi, H. (2020: 104-108) Menjelaskan Ada empat aspek yang menjadi dampak langsung serta menjadi focus perhatian dari penggunaan model PSI-BK sebuah alaternetif Merdeka Belajar di Era Revolusi Industri 4.0, diantaranya :

\section{Sikap Toleransi yang Baik}

Dosen memberikan keteladalan terkait toleransi dalam interaksinya bersama mahasiswa. Pembelajaran berproses dengan dengan menggunakan sistem sosial toleransi terhadap keberagaman. Materipun dirancang dengan menonjolkan sikap toleransi yang sudah dicontohkan oleh Rasulullah Muhammad SAW serta para 
pengikutnya. Oleh karena itu, akan berdampak langsung dalam mengembangkan sikap toleransi mahasiswa dengan baik. Dosen dapat mengukur ketercapian sikap toleransi mahasiswa dengan menggunakan rubrik penilaian sikap dengan indikator yang jelas. Adapun instrument yang digunakan untuk mengukur baik atau kurang baiknya sikap toleransi mahasiswa berikut ini :

\section{Keterampilan Berkolaborasi}

Pelaksanaan model PSI-BK bagi dosen akan berdampak langsung terhadap peningkatan keterampilan berkolaborasi mahasiswa, karena syntax, prinsip reaksi dan sistem sosial yang dikembangkan dalam model ini dapat memotivasi, mempraktikkan kemampuan berkolaborasi dalam proses perkulihan. Oleh karena itu, peneliti merumuskan indikator kolaborasi dengan rinci. Adapun rubriknya dapat disimak berikut ini:

\section{Komunikasi yang Santun}

Pelaksanaan model PSI-BK bagi dosen akan berdampak langsung terhadap peningkatan kemampuan komunikasi yang santun bagi mahasiswa, karena syntax, prinsip reaksi dan sistem sosial yang dikembangkan dalam model ini dapat memotivasi, mempraktikkan kemampuan komunikasi yang santun dalam proses perkulihan. Oleh karena itu, peneliti merumuskan indikator santun dengan rinci. Adapun rubriknya dapat disimak berikut ini :

\section{PEMAHAMAN YANG BAIK TERHADAP MATERI}

Penerapan model PSI-BK oleh dosen akan berdampak langsung terhadap peningkatan pemahaman mahasiswa terhadap materi sejarah Islam, karena karakteristik model, syntax, prinsip reaksi dan sistem sosial yang dikembangkan dalam model ini dapat memotivasi mahasiswa untuk lebih merdeka dalam belajar dan bagi masa depan mahasiswa serta memperoleh materi sejarah islam dengan frame berpikir yang moderatisme. Bahan ajar dan penugasan dalam perkuliahan dirancang agar mahasiswa mampu berpikir kritis dan mampu mensisntesis berbagai persoalan kontemporer yang dialami umuat Islam. Oleh karena itu, peneliti merancang instrument untuk mengukur ketercapian pemahaman materi dengan baik melalui kuis, UTS dan UAS. Pengetahuan konseptual dapat di ukur melalui kuis saat selesai perkuliahan dan UTS dan UAS dirancang soalnya menggunakan HOTS, dengan kata lain soal yang di buat merujuk taksonomi Bloomminimal setiap pertanyaan menggunakan kata kunci C4 (cognitive 4) keatas.

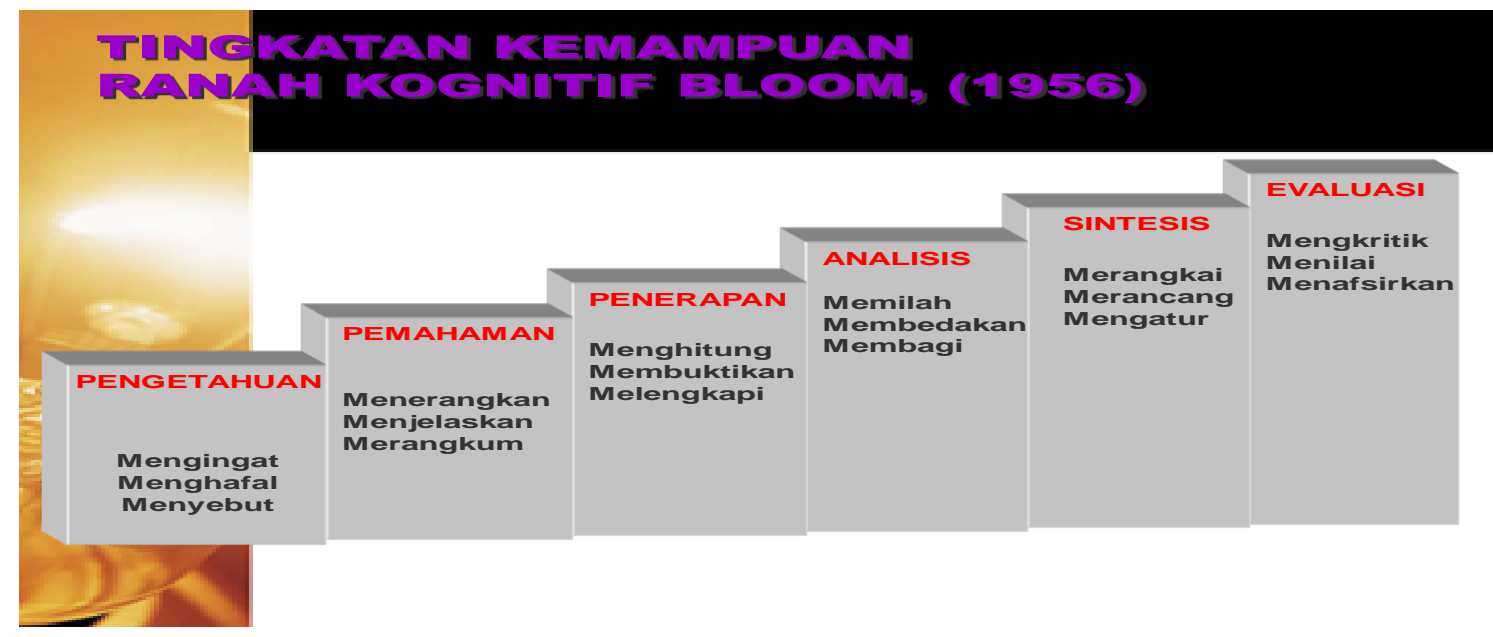




\section{SIMPULAN}

Perguruan tinggi idealnya sebagai mata air bagi kemajuan dan pembangunan bangsa, Kebijakan Merdeka Belajar sejatinya menjadi kultur baru yang harus tetap di bumikan dalam proses belajar mengajar yang otonom dan inovatif berbasis kebutuhan hidup, Model Pembelajaran Sejarah Islam Berbasis Kebhinnekaan (PSI-BK) Sebuah Alternatif Merdeka Belajar di Era Revolusi Industri 4.0, dimana dalam model PSI-BK ini yakni lebih mengedepankan siswa dan mahasiswa agar memiliki (1) sikap toleransi yang baik, (2) keterampilan berkabolarasi, (3) komunikasi yang santun, dan (4) pemahaman yang baik terhadap materi sehingga model PSI-BK ini relevan visi, misi merdeka belajar di era revolusi industri 4.0 sekarang dan masa yang akan datang, maka di harapkan semoga model PSI-BK Ini relavan sesui jiwa zamannya. Dimana Pendidikan Tinggi kedepannya memerlukan perubahan cara pandang yang bersifat mendasar, diantaranya: Perubahan dari berpikir hanya fokus tentang kehidupan masyarakat lokal menjadi berpikir ke masyarakat global (dunia), (b) Perubahan dari kompetisi semata menjadi partisipasi, sinergi, dan kolaborasi yang saling menguntungkan serta dijiwai semangat demokratisasi dalam pendidikan dan praktek berkewarganegaraan, dan(c) perubahan dari mengejar pertumbuhan ekonomi ke perkembangan kemanusiaan untuk menciptakan keadilan sosial dengan senantiasa menggerus ketimpangan dengan pemerataan.

\section{REFERENSI}

Afwan, B., Suryani, N., \& Ardianto, D. T. (2020, May). Analisis Kebutuhan Pembelajaran Sejarah Di Era Digital. In PROCEEDING.

ARIFIN, S., \& Muslim, M. O. H. (2020). Tantangan Implementasi Kebijakan "Merdeka Belajar, Kampus Merdeka" pada Perguruan Tinggi Islam Swasta di Indonesia. Jurnal Pendidikan Islam Al-Ilmi, 3(1).

Effendi, H. Dkk. (2020). Buku Model Pembelajaran Sejarah Islam Berbasis Kebhinnekaan (PSI-BK) Sebagai Daya Tangkal Radikalisme di Perguruan Tinggi. Pekalongan PT Nasya Expanding Management. NEM. Pekalongan.

Dekker, I. N. (1975). Sejarah Pergerakan Nasional Indonesia. Malang: Almamater.

Kusworo, Budi. The Implementation of Islam as Rahmah Li Al-'Alamin in Indonesia: Contributions, Challenges and Opportunitie. AJIS : Academic Journal of Islamic Studies vol. 2, no. 2, 2017 Postgraduate of STAIN Curup - Bengkulu | p-ISSN 2580-3174, e-ISSN 2580-3190 Available online: http://journal.staincurup.ac.id/index.php/AJIS.

Laksana, S. D. (2016). Integrasi Empat Pilar Pendidikan (UNESCO) Dan Tiga Pilar Pendidikan Islam. $A L$ IDARAH: JURNAL KEPENDIDIKAN ISLAM, 6(1).

McCullagh, C. (2004). Logic of History, Perspektif Posmodernisme. Yogyakarta: Lilin Persada Press.

Mu'amalah, K. (2020). Merdeka Belajar sebagai Metode Pendidikan Islam dan Pokok Perubahan (Analisis Pemikiran KH Hamim Tohari Djazuli). Jurnal Tawadhu, 4(1), 977-994.

Mustaghfiroh, S. (2020). Konsep "Merdeka Belajar" Perspektif Aliran Progresivisme John Dewey. Jurnal Studi Guru Dan Pembelajaran, 3(1), 141-147.

Sesfao, M. (2020, March). Perbandingan Pemikiran Pendidikan Paulo Freire Dengan Ajaran Tamansiswa Dalam Implementasi Merdeka Belajar. In Seminar Nasional Pendidikan (Vol. 1, No. 1).

Siregar, N., Sahirah, R., \& Harahap, A. A. (2020). Konsep Kampus Merdeka Belajar di Era Revolusi Industri 4.0. Fitrah: Journal of Islamic Education, 1(1), 141-157.

Sugiyono.(2016). MetodePenelitianPendidikanPendekatanKuantitatifKualitatifdanr\&d. edisi ke-24.Alfabeta, Bandung

Tohir, M. (2020). Merdeka Belajar: Kampus Merdeka.

Wulandari, Ayik., Handayani, Putri., Prasetyo, Dody Rahayu. (2019). Pembelajaran Ilmu Pengetahuan Alam Berbasis EMC (Education Mini Club) sebagai Solusi Menghadapi Tantangan Pendidikan dI Era Revolusi Industri 4.0. Thabiea 2 (1).

Yamin, M., \& Syahrir, S. (2020). Pembangunan Pendidikan Merdeka Belajar (Telaah Metode Pembelajaran). Jurnal Ilmiah Mandala Education, 6(1).

Undang-undang Republik Indonesia Nomor 20 tahun 2003 tentang SistemPendidikan Nasional. 
Undang-undang Republik Indonesia Nomor14 tahun 2005 tentang Guru dan Dosen

Undang Undang Republik Indonesia Nomor 12 Tahun 2012 tentang Pendidikan Tinggi’

Wawancara dengan Dosen Pendidikan Sejarah Institut Pendidikan Tapanuli Seltan Januari 2019.

Wawancara dengan Dosen Pendidikan kewarganegaraan dan Pendidikan Guru Sekolah Dasar Universitas Bung Hatta Padang Februari 2019.

Wawancara dengan mahasiswa Pendidikan Sejarah Institut Pendidikan Tapanuli Seltan Januari 2019.

Wawancara dengan Mahasiswa Pendidikan kewarganegaraan dan Pendidikan Guru Sekolah Dasar Universitas Bung Hatta Padang Februari 2019. 